\title{
Age and HPV type as risk factors for HPV persistence after loop excision in patients with high grade cervical lesions: an observational study
}

\author{
Laurențiu Pirtea ${ }^{1,7}$, Dorin Grigoraş ${ }^{1,7}$, Petru Matusz ${ }^{2,7}$, Marilena Pirtea ${ }^{3,7}$, Lavinia Moleriu ${ }^{4,7}$, Anca Tudor ${ }^{4,7}$,
} Răzvan llina ${ }^{5,7^{*}}$, Cristina Secoşan ${ }^{3,7}$, Florin Horhat ${ }^{6,7}$ and Octavian Mazilu ${ }^{5,7}$

\begin{abstract}
Background: Persistent infections with high risk human papillomaviruses (HR-HPV) cause virtually all cervical cancers.

Methods: An observational study was conducted aiming to estimate the rate of HPV infection persistence after LEEP in patients with high grade squamous intraepithelial lesions (HSIL). Moreover, the study investigated if persistence is age related. For this reason a total of 110 patients were included between January 2010 and June 2015.

Results: At 6 months after LEEP the overall HPV infection persistence rate was $40.9 \%$, at 12 months $20 \%$ and at 18 months $11.8 \%$. Type 16 showed the highest persistence rate: $27.3 \%$ at 6 months, $12.7 \%$ at 12 months and $10 \%$ at 18 months after LEEP. The persistence for HPV type 16 at 6 months after LEEP was significantly higher in the group $>=36.5$ years old compared to the persistence rate in the group $<36.5$ years old $(p=0.0027, \operatorname{RR}=2.75$, $95 \%(1.34 ; 5.64))$ (see Table 3).
\end{abstract}

Conclusions: LEEP does not completely eradicate HPV infection. HPV persistence rate after LEEP is higher in infections with type 16 and in women older than 36.5 years.

Keywords: HPV type 16, Age, Infection persistence, LEEP

\section{Background}

Virtually all cervical cancers are caused by persistent high-risk human papillomaviruses (HR-HPV) infection [1-3]. One of the indirect factors for HPV persistence is considered to be the old age [4]. Genital HPV infection is presumably the most prevalent sexually transmitted infection [4]. A particularly high risk for the acquisition of HPV infection is described in young women, soon after they become sexually active [5].

The prevalence of HPV infection in women older than 30 is significantly lower than that described in younger

\footnotetext{
* Correspondence: razvanilina@yahoo.co.uk

5Department of Surgery, University of Medicine and Pharmacy "Victor Babeş", str. Dimitrie Cantemir, nr. 1, Zip Code 300001 Timişoara, Romania

${ }^{7}$ County Hospital Timișoara, Hector street, number 1, Timișoara, Romania

Full list of author information is available at the end of the article
}

women at the mean age of the first sexual intercourse. Despite the fact that these infections are mostly controlled or self-limited by the immune system, the determinants of age-specific prevalence variation in older women remain uncertain [6]. It is considered that the clearance of the infection is immune-mediated and mostly type-specific.

The management of women with cervical intraepithelial neoplasia (CIN) is crucial, given that improper management may increase the risk of developing cervical cancer, whereas overtreatment increases the risk of complications related to preterm delivery or other. Therefore, appropriate management is essential in terms of cancer prevention $[7,8]$.

The standard procedure for conservative management of high-grade CIN is large loop excision of the transformation 
zone (LEEP) or conization. Although this treatment is generally sufficient, resulting in a complete cure, Arbyn et al [9] reported an average of $10 \%$ residual or recurrent disease in the treated cases.

Some HPV infections may persist, despite the relatively high post-conization HPV clearance rate [10]. A number of risk factors for residual or recurrent disease have been identified in the treatment of CIN lesions. According to Nam and Heymans, these are: age, menopause status, cytology grade, margin involvement and HPV viral load [10, 11].

The objectives of our study were to estimate the rate of HPV infection persistence after LEEP in patients with high grade squamous intraepithelial lesions (HSIL) and to investigate if persistence is age related.

In Romania cervical cancer is the first leading cause of cancer deaths in women aged 15 to 44 years, with over 4300 new cases diagnosed each year. Infection with HR HPV types was found in $86.8 \%$ of the cases and the prevalence HPV type 16 is $45 \%$ among women with high grade lesions [12]. A national program that started in 2012 for the screening and prevention of cervical cancer is still ongoing in Romania. In addition, all women aged over 16 can benefit from a free Pap smear. Moreover, the cases with cytological abnormalities are referred to specialized centers.

\section{Methods}

Patient selection: We performed an observational study. We included in the study all patients with HSIL cytology on PAP smear that had no previous treatment for cervical lessions, who were referred for LEEP to the department of obstetrics and gynecology of the University of Medicine and Pharmacy "Victor Babeș" Timișoara, between January 2010 and June 2015. Patients were first evaluated trough the national screening program. Those with cytological abnormalities were referred to our center. Another Pap smear was performed and patients with HSIL were referred to our department. All patients referred for LEEP had Pap smears interpreted by the same pathology team. Conventional cytology was performed and evaluated according to the criteria of Bethesda 2001. All patients were evaluated by colposcopy and International Federation for Cervical Pathology and Colposcopy (IFCPC) criteria were used. All patients underwent LEEP under colposcopic vision after Lugol solution application. With the procedure all colposcopically abnormal findings were excised, aiming for a tissue depth of at least $6 \mathrm{~mm}$. Every procedure was performed by the same team of surgeons. HPV DNA testing was performed before LEEP in all cases and repeated during the follow up visits at 6,12 and 18 months after surgery. The investigated outcome was HPV persistence on HPV DNA test at 6, 12 and 18 months after LEEP. Patients who were negative for HPV DNA before LEEP were excluded from the study. All samples were examined using LINEAR ARRAY HPV Genotyping Test (CE-IVD), based on reverse hybridization of amplicons. The DNA of $37 \mathrm{HPV}$ types $(6,11,16,18,26,31,33,35,39,40,42,45,51,52$, $53,54,55,56,58,59,61,62,64,66,67,68,69,70,71,72$, $73,81,82,83,84$, IS39 and CP6108) was detected in cervical samples by multiplex PCR targeted to the conserved L1 region of the viral genome. The Gene Amp PCR System 9700 was used for genotyping test according to the manufacturer's instructions. Automated hybridization and detection of HPV DNA was done on the ProfiBlot 48 (Tecan Trading AG, Zurich, Switzerland).

All specimens were sent to histopathological exam. Patients with positive resection margins after LEEP were excluded from the study.

Follow up visits were scheduled at 6,12 and 18 months after surgery. DNA HPV testing was performed for each patient at each visit.

Informed consent was obtained from every patient prior to their inclusion in the study. All procedures have been performed in accordance with the ethical standards laid down in the 1964 Declaration of Helsinki and its later amendments and were approved by the Institutional Review Board and Ethical Committee of "Victor Babeş" University of Medicine and Pharmacy Timişoara - reference number of ethics approval 20/2010.

Statistical analysis was conducted using the following software SPSS v17, Epi Info 7 and Microsoft Excel. For this data we computed a descriptive statistics, we used parametrical statistical tests ( $\mathrm{Z}$ test for proportion) and we performed a risk analysis using a chi square test and risk indicators. The cutoff point was considered the median age in our group. The $\mathrm{Z}$ test for proportion was computed in order to measure the persistence rate of HPV types. We performed a risk analysis considering as an exposure the age above the median age in our group.

\section{Results}

A total of 129 patients were referred to our clinic with HSIL on PAP Smear test. Positive margins after LEEP were found in 7 patients and they were excluded from the study. The HPV test was negative in 12 patients with HSIL and they were also excluded. The remaining 110 patients were followed up. Data collection was complete for all 110 patients at each time point and the study visits were balanced individually for every patient at 6 months apart. The HPV types detected at the start of the trial were $49.1 \%$ type $16,21.8 \%$ type $18,20 \%$ type $31,26.4 \%$ type $33,10.9 \%$ type $35,6.4 \%$ type $45,30 \%$ type $52,9.1 \%$ type $58,7.3 \%$ type $6,4.5 \%$ type 11 and $4.5 \%$ other types. The co-infection with multiple HR HPV types was found in $68.2 \%$ of our patients. At 6 months after LEEP the overall persistence was $40.9 \%$ 
(45 patients), at 12 months $20 \%$ (22 patients) and at 18 months $11.8 \%$ (13 patients). The rate of persistence in our group at 6,12 and 18 months for each HPV type and the distribution of HPV types (including patients with multiple types) found before LEEP and the distribution of HPV types persistent at 6,12 and 18 months are shown in Table 1.

The HPV clearance rate (proportion) after LEEP is statistical significant at 6 and 12 months. The overall HPV persistence rate was lower at 18 months compared to 12 months, but the difference was not statistically significant (Table 2).

The age distribution is shown in Fig. 1 and Table 3. The median age in our group was 36.5 years. We found a higher persistence rate for HPV16 in patients who were older than 36.5 years and in patients presenting coinfection (by co-infection we mean infection with at least two different HPV types). We performed a comparative analysis for the HPV type 16 infection rate before LEEP and at each follow up visit and we found that the clearance rate in the group $>=36.5$ years was significantly lower in the first 6 months $(p=0.0027, \mathrm{RR}=2.75$, $95 \%(1.34 ; 5.64))$. All the results are presented in Table 4. For co-infections we performed the same analysis and we found that age over 36.5 years was associated with a higher persistence rate during the first 12 months $(p=0.01, \mathrm{RR}=2.67,95 \% \quad(1.13 ; 6.30))$. All of these results are shown in Table 5 .

We found no significant differences between the persistence rate for co-infections including type 16 versus infection with type 16 alone. The results are shown in Table 6 .

\section{Discussion}

Despite the removal of the entire lesion by cone excision, with negative margins, the HPV infection can persist in some cases. Studies investigating the clearance/persistence of HPV infection after LEEP have reported that age, lesion grade, and margin status are risk factors for HPV persistence.

Since the presence of positive margins is considered a major factor for HPV persistence and disease recurrence and progression, we excluded patients with positive margins after resection from our study, as we wanted to investigate the persistence of HPV infection in patients with negative margins.

Although LEEP does not completely eradicate HPV infection, our results indicate that most HR-HPV infections are cleared after LEEP with negative margins. The clearance rate is increasing gradually after surgery. Our persistence rate was $40.9 \%$ at 6 months, $20 \%$ at 12 months and $11.8 \%$ at 18 months. We identified a persistence rate higher than the one reported by other authors: Kim et al [13] reported a persistence rate of $14.3 \%, 2.2 \%$ and $1.1 \%$ at 6,12 and 18 months. High persistence rates, similar to ours, were found only by Song et al [14], who reported a persistence rate of $43.8 \%$ at 6 months in patients with high viral load before LEEP [14]. We consider that our criteria for patient selection and the fact that only patients with HSIL were included is the cause for our high persistence rate.

Our results indicate that HPV type 16 has the lowest clearance rate. Kim et al [13], Heymans et al [11] and Nam et al [10] also found that HPV type 16 is a factor for infection persistence after treatment. Therefore, patients with HPV type 16 should be carefully monitored after LEEP $[10,11,13]$.

The value of age as a factor that favors HPV persistence after LEEP is a subject of controversy. Costa et al 2003 and Sarian et al 2004 found that women older than 35 years old had a significantly higher risk for HPV

Table 1 Frequency table for all HPV types

\begin{tabular}{|c|c|c|c|c|}
\hline HPV Types & Before LEEP & 6 months & 12 months & 18 months \\
\hline 16 & 54 (49.1\%) & $30(27.3 \%)$ & 14 (12.7\%) & $11(10.0 \%)$ \\
\hline 18 & $24(21.8 \%)$ & $5(4.5 \%)$ & 1 (0.9 \%) & 0 (0 \%) \\
\hline 31 & 22 (20 \%) & 2 (1.8\%) & $0(0 \%)$ & $0(0 \%)$ \\
\hline 33 & 29 (26.4 \%) & $4(3.6 \%)$ & 1 (0.9 \%) & 0 (0 \%) \\
\hline 35 & 12 (10.9\%) & $0(0 \%)$ & 0 (0 \%) & $0(0 \%)$ \\
\hline 45 & 7 (6.4%) & $0(0 \%)$ & 0 (0 \%) & 0 (0 \%) \\
\hline 52 & $33(30.0 \%)$ & 9 (8.2\%) & 4 (3.6 \%) & 0 (0 \%) \\
\hline 58 & 10 (9.1\%) & 2 (1.8\%) & 1 (0.9 \%) & $0(0 \%)$ \\
\hline 6 & $8(7.3 \%)$ & 2 (1.8\%) & 2 (1.8\%) & $2(1.8 \%)$ \\
\hline 11 & $5(4.5 \%)$ & 1 (0.9 \%) & 1 (0.9 \%) & 1 (0.9 \%) \\
\hline other types & $5(4.5 \%)$ & $0(0 \%)$ & $0(0 \%)$ & $0(0 \%)$ \\
\hline coinfections & 75 (68.2 \%) & 10 (9.1 \%) & $2(1.8 \%)$ & 1 (0.9 \%) \\
\hline total number of patients with HPV infection & $110(100.0 \%)$ & 45 (40.9\%) & $22(20.0 \%)$ & $13(11.8 \%)$ \\
\hline
\end{tabular}

Frequency table for all HPV type - before LEEP, at 6 months, 12 months and 18 months 
Table 2 The evolution in time for infections

\begin{tabular}{|c|c|c|c|c|c|c|c|}
\hline \multicolumn{2}{|c|}{ Moments of time } & \multicolumn{2}{|l|}{ Type 16 HPV } & \multicolumn{2}{|c|}{ Type 16 + other HPV types } & \multicolumn{2}{|l|}{ Co-infections } \\
\hline & & $\begin{array}{l}p \text { value } \\
\text { significance }\end{array}$ & $\begin{array}{l}\text { Level of } \\
\text { significance }\end{array}$ & $\begin{array}{l}p \text { value } \\
\text { significance }\end{array}$ & $\begin{array}{l}\text { Level of } \\
\text { significance }\end{array}$ & $\begin{array}{l}p \text { value } \\
\text { significance }\end{array}$ & $\begin{array}{l}\text { Level of } \\
\text { significance }\end{array}$ \\
\hline \multirow{3}{*}{$\begin{array}{l}\text { Before } \\
\text { LEEP }\end{array}$} & 6 months & $0001^{\mathrm{s}}$ & 0,01 & $<0001^{\mathrm{s}}$ & 0001 & $<0001^{\mathrm{s}}$ & 0001 \\
\hline & 12 months & $<0001^{5}$ & 0001 & $<0001^{\mathrm{s}}$ & 0,001 & $<0,001^{\mathrm{s}}$ & 0,001 \\
\hline & 18 months & $<0,001^{\mathrm{s}}$ & 0,001 & $<0,001^{\mathrm{s}}$ & 0,001 & $<0,001^{\mathrm{s}}$ & 0,001 \\
\hline \multirow[t]{2}{*}{6 months } & 12 months & $0,011^{5}$ & 0,05 & $0,340^{\text {ns }}$ & 0,05 & $0,037^{5}$ & 0,05 \\
\hline & 18 months & $0,002^{5}$ & 0,01 & $0,249^{\text {ns }}$ & 0,05 & $0,013^{5}$ & 0,05 \\
\hline 12 months & 18 months & $0,675^{\text {ns }}$ & 0,05 & $0,824^{\text {ns }}$ & 0,05 & $0,995^{\text {ns }}$ & 0,05 \\
\hline
\end{tabular}

The evolution in time for infections: HPV 16, HPV 16 and at least another HPV type and for co-infections ( ${ }^{5}$ - significant difference, ${ }^{\text {ns }}$ - insignificant difference)

persistence after LEEP $[15,16]$. On the other hand, more recent studies performed by Nam et al 2009 and Park et al [17] found no correlation between age of patient and HPN infection persistence after LEEP [10, 17]. Our results indicate that age is a risk factor for the persistence after conization only for HPV type 16. At the end of our study the persistence for HPV16 was $7.3 \%$ for the group $>=36.5$ years old and $2.7 \%$ for the group $<36.5$ years old (with $p=0.1120, \mathrm{RR}=2.67,95 \% \quad(0.75$; 9.53)). In the first 6 months after LEEP we have significant differences between this two group ages $(p=0.0027$, $\mathrm{RR}=2.75,95 \% \quad(1.34 ; 5.64))$.

We consider this information valuable, as HPV type 16 seems to have the highest pathogenicity. We did not find in literature data about age as a risk factor for the persistence of HPV type 16 alone. For that reason, we consider that this adds value to our study.
The value of age as a predictor for disease recurrence is also subject for debate: Verguts et al 2006 found higher age at LEEP is associated with higher rate of disease recurrence, while Ryu et al 2012 found no correlation between age and disease recurrence $[18,19]$. Since most recurrences are associated with the persistence of HPV type 16, we consider that women with HPV type 16 and older than 36.5 years should be closely followed.

In our study group we identified a high percentage (68 \%) of co-infection with multiple HPV types. According to the findings of Jaisamrarn et al [20], concomitant HPV infection increase the risk of progression to a lesion, suggesting that multiple HPV infections could influence disease progression. We consider that our high rate of patients co-infected with multiple HPV types is due to the selection of patients with HSIL only [20].

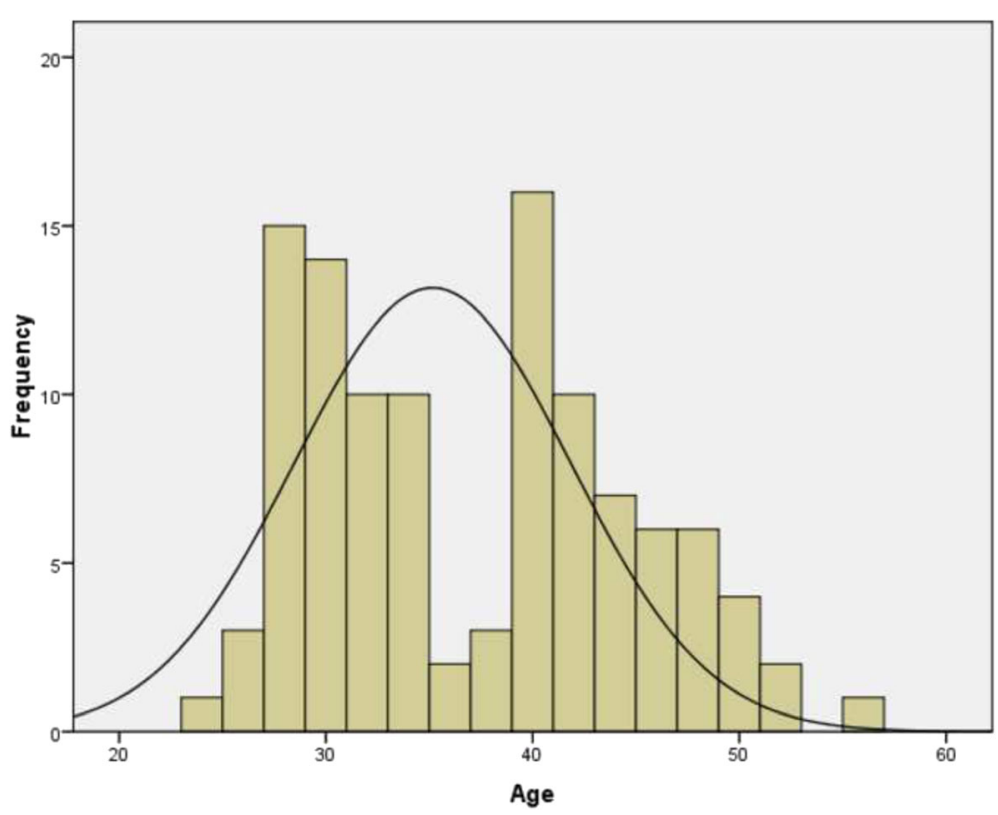

Fig. 1 The age distribution histogram - the median age is 36.5 years. This graphic shows patient distribution according to the age of the patients 
Table 3 The age distribution

\begin{tabular}{llllll}
\hline Age & Frequency & Percent & Age & Frequency & Percent \\
\hline 24 & 1 & 0,91 & 40 & 7 & 6,36 \\
26 & 3 & 2,73 & 41 & 5 & 4,55 \\
27 & 5 & 4,55 & 42 & 5 & 4,55 \\
28 & 10 & 9,09 & 43 & 1 & 0,91 \\
29 & 8 & 7,27 & 44 & 6 & 5,45 \\
30 & 6 & 5,45 & 45 & 2 & 1,82 \\
31 & 5 & 4,55 & 46 & 4 & 3,64 \\
32 & 5 & 4,55 & 47 & 4 & 3,64 \\
33 & 7 & 6,36 & 48 & 2 & 1,82 \\
34 & 3 & 2,73 & 49 & 3 & 2,73 \\
36 & 2 & 1,82 & 50 & 1 & 0,91 \\
37 & 3 & 2,73 & 52 & 2 & 1,82 \\
39 & 9 & 8,18 & 55 & 1 & 0,91 \\
\hline
\end{tabular}

The age distribution, the age frequency and the corresponding percentage for our group

The limitation of our study is that we tested for HR-HPV only patients with HSIL and this artificially increases the percentage of HR- HPV positive patients.

The strengths of the study are represented by the nature of the study and the fact that only patients with HSIL were selected. This way we investigated the very category of patients that are likely to be infected with HR-HPV and that are exposed to recurrence after LEEP and disease progression to cancer.

Table 4 Risk analysis for the persistence of HPV 16

\begin{tabular}{lllll}
\hline Volume $N=110$ & HPV 16+ & HPV 16- & Total & $\begin{array}{l}p \text {-value } \\
\text { Risk analysis }\end{array}$ \\
\hline 6 Months & 22 & 33 & 55 & $p=0.0027$ \\
$>=36.5$ & 8 & 47 & 55 & $\mathrm{RR}=2.75$ \\
$<36.5$ & 30 & 80 & 110 & $95 \% \epsilon(1.34 ; 5.64)$ \\
Total & & & & \\
12 Months & 10 & 45 & 55 & $p=0.0861$ \\
$>=36.5$ & 4 & 51 & 55 & $\mathrm{RR}=2.5$ \\
$<36.5$ & 14 & 96 & 110 & $95 \% \epsilon(0.83 ; 7.49)$ \\
Total & & & & \\
18 Months & 8 & 47 & 55 & $p=0.1120$ \\
$>=36.5$ & 3 & 52 & 55 & $\mathrm{RR}=2.67$ \\
$<36.5$ & 11 & 99 & 110 & $95 \% \epsilon(0.75 ; 9.53)$ \\
Total & & & & \\
\hline
\end{tabular}

Risk analysis for the persistence of HPV 16 (the contingence tables, the $p$ values, the relative risk values and the risk inference intervals for $95 \%$ of the population). With HPV16+ we marked the patients having HPV16, and with HPV16- the patients without this HPV type. We considered as an exposure the age above 36.5 years
Table 5 Risk analysis for the persistence of HPV coinfections

\begin{tabular}{lllll}
\hline Volume $N=110$ & HPV + & HPV- & Total & $\begin{array}{l}p \text {-value } \\
\text { Risk analysis }\end{array}$ \\
\hline 6 Months & & & & \\
$>=36.5$ & 32 & 23 & 55 & $p<0.001$ \\
$<36.5$ & 13 & 42 & 55 & $R=2.46$ \\
Total & 45 & 65 & 110 & $95 \% \epsilon(1.45 ; 4.16)$ \\
12 Months & & & & \\
$>=36.5$ & 16 & 39 & 55 & $p=0.0171$ \\
$<36.5$ & 6 & 49 & 55 & $R R=2.67$ \\
Total & 22 & 88 & 110 & $95 \% \epsilon(1.13 ; 6.30)$ \\
18 Months & & & & \\
$>=36.5$ & 8 & 47 & 55 & $p=0.3755$ \\
$<36.5$ & 5 & 50 & 55 & $R R=1.60$ \\
Total & 13 & 97 & 110 & $95 \% \epsilon(0.55 ; 4.58)$
\end{tabular}

Risk analysis for the persistence of HPV coinfections (the contingence tables, the $p$ values, the relative risk values and the risk inference intervals for $95 \%$ of the population). We marked with co-infections (HPV+) the patients who have at least two different HPV types and with HPV- patients who have just one HPV type. We considered as an exposure the age above 36.5 years

\section{Conclusions}

Although LEEP does not completely eradicate HPV infection, our results indicate that most HR-HPV infections are cleared after LEEP with negative margins.

Moreover, HPV type 16 and age over 36.5 years are factors that favor infection persistence.

Table 6 Risk analysis for the persistence of HPV 16 with other HPV types and only HPV16

\begin{tabular}{lllll}
\hline Volume & $\begin{array}{l}\text { HPV 16+ } \\
\text { other HPV types }\end{array}$ & HPV 16 & Total & $\begin{array}{l}p \text {-value } \\
\text { Risk analysis }\end{array}$ \\
\hline 6 Months & & 15 & 22 & $p=0.77$ \\
$>=36.5$ & 7 & 5 & 8 & RR $=0.85$ \\
$<36.5$ & 3 & 20 & 30 & $95 \% \epsilon(0.28 ; 2.51)$ \\
Total & 10 & & & \\
12 Months & & 10 & 10 & $p=0.019$ \\
$>=36.5$ & 0 & 2 & 4 & $R R=0$ \\
$<36.5$ & 2 & 12 & 14 & undefined \\
Total & 2 & & & \\
18 Months & & 8 & 8 & $p=0.102$ \\
$>=36.5$ & 0 & 2 & 3 & RR $=0$ \\
$<36.5$ & 1 & 10 & 11 & undefined \\
Total & 1 & 10 &
\end{tabular}

Risk analysis for the persistence of HPV 16 with other HPV types and only HPV16 (the contingence tables, the $p$ values, the relative risk values and the risk inference intervals for $95 \%$ of the population). We considered as an exposure the age above 36.5 years 


\section{Additional file}

Additional file 1: Datasets. (XLS $106 \mathrm{~kb}$ )

\begin{abstract}
Abbreviations
CIN: Cervical intraepithelial neoplasia; HPV: Human papilloma virus; HRHPV: High-risk human papilloma virus; HSIL: High grade squamous intraepithelial lesions; IFCPC: International Federation for Cervical Pathology and Colposcopy; LEEP: Loop excision of the transformation zone;
\end{abstract}

\section{Acknowledgements}

Not applicable.

\section{Funding}

This article was supported by the grant PII-C2-TC-2014-06 University of Medicine and Pharmacy "Victor Babeș" Timișoara, Romania.

\section{Availability of data and materials}

The datasets on which the conclusions of the manuscript rely are presented in an Additional file 1.

\section{Authors' contributions}

LP, MP and CS performed the surgery and conceived and designed the study, were responsible with acquisition of data. DG, OM, PM, LM, AT, FH performed the analysis and interpretation of data. RI participated in the design of the study, drafted the manuscript and gave the final approval of the version to be published. All authors read and approved the final manuscript.

\section{Authors' information}

L Pirtea - PhD and Senior Consultant of Department of Obstetrics and Gynecology Timisoara County Hospital.

R Ilina - PhD and Senior Consultant of Department of Surgery Timisoara County Hospital.

D Grigoraş - Professor, Senior Consultant and Chief of Department of Obstetrics and Gynecology Timisoara County Hospital.

O Mazilu - Professor, Senior Consultant and Chief of Department of Surgery Timisoara County Hospital.

P Matusz - Professor Department of Anatomy University of Medicine and Pharmacy "Victor Babeş" Timişoara, Romania.

M Pirtea - MD and Senior Consultant Department of Obstetrics and Gynecology, County Hospital Timişoara, Romania.

L Moleriu - PhD and Senior Consultant of Department of Informatics and Biostatistics University of Medicine and Pharmacy "Victor Babeş" Timişoara, Romania.

A Tudor - PhD and Senior Consultant of Department of Informatics and Biostatistics University of Medicine and Pharmacy "Victor Babeş" Timişoara, Romania.

C Secoşan - MD and SHO Department of Obstetrics and Gynecology, County Hospital Timişoara, Romania.

F Horhat - PhD and Senior Consultant of Department of Microbiology University of Medicine and Pharmacy "Victor Babeş" Timişoara, Romania.

\section{Competing interests}

The authors declare that they have no competing interests.

\section{Consent for publication}

Not applicable.

\section{Ethics approval and consent to participate}

Informed consent was obtained from all patients prior to their inclusion in the study. All procedures have been performed in accordance with the ethical standards laid down in the 1964 Declaration of Helsinki and its later amendments and were approved by the Institutional Review Board and Ethical Committee of "Victor Babeş" University of Medicine and Pharmacy Timişoara - reference number of ethics approval 20/2010.

\section{Author details}

'Department of Obstetrics and Gynecology, University of Medicine and Pharmacy "Victor Babeş", Timişoara, Romania. 'Department of Anatomy,
University of Medicine and Pharmacy "Victor Babeş", Timişoara, Romania. ${ }^{3}$ Department of Obstetrics and Gynecology, County Hospital Timişoara, Timișoara, Romania. ${ }^{4}$ Department of Informatics and Biostatistics, University of Medicine and Pharmacy "Victor Babeş", Timişoara, Romania. "Department of Surgery, University of Medicine and Pharmacy "Victor Babeş", str. Dimitrie Cantemir, nr. 1, Zip Code 300001 Timişoara, Romania. 'Department of Microbiology, University of Medicine and Pharmacy "Victor Babeş", Timişoara, Romania. ${ }^{7}$ County Hospital Timișoara, Hector street, number 1, Timișoara, Romania.

Received: 19 March 2016 Accepted: 27 September 2016 Published online: 06 October 2016

\section{References}

1. Bosch FX, de Sanjosé S. Chapter 1: Human papillomavirus and cervical cancer-burden and assessment of causality. J Natl Cancer Inst Monogr. 2003;31:3-13. PMID:12807939.

2. Bosch FX, Lorincz A, Muñoz N, Meijer CJLM, Shah KV. The causal relation between human papillomavirus and cervical cancer. J Clin Pathol. 2002; 55(4):244-65. PMCID:PMC1769629.

3. zur Hausen H. Papillomaviruses causing cancer: evasion from host-cell control in early events in carcinogenesis. J Natl Cancer Inst. 2000;92(9):6908. PMID:10793105

4. Moscicki $A B$, Schiffman $M$, Burchell $A$, et al. Updating the natural history of human papillomavirus and anogenital cancers. Vaccine. 2012;30 Suppl 5: F24-33. doi:10.1016/j.vaccine.2012.05.089. PMCID:PMC3700362.

5. Lowy DR, Solomon D, Hildesheim A, Schiller JT, Schiffman M. Cancer. 2008; 113(7 Suppl):1980-93. doi:10.1002/cncr.23704. PMID:18798536.

6. Franceschi S, Herrero R, Clifford GM, et al. Variations in the age-specific curves of human papillomavirus prevalence in women worldwide. Int J Cancer. 2006;119(11):2677-84. PMID:16991121.

7. Insinga RP, Glass AG, Rush BB. Diagnoses and outcomes in cervical cancer screening: a population-based study. Am J Obstet Gynecol. 2004;191(1):10513. doi:10.1016/j.ajog.2004.01.043S0002937804001048. PMID:15295350.

8. Kyrgiou M, Koliopoulos G, Martin-Hirsch P, Arbyn M, Prendiville W, Paraskevaidis E. Obstetric outcomes after conservative treatment for intraepithelial or early invasive cervical lesions: systematic review and metaanalysis. Lancet. 2006;367(9509):489-98. doi:10.1016/S0140-6736(06)68181-6. PMID:16473126.

9. Arbyn M, Sasieni P, Meijer CJ, Clavel C, Koliopoulos G, Dillner J. Chapter 9: Clinical applications of HPV testing: a summary of meta-analyses. Vaccine. 2006;24 Suppl 3:S3/78-89. PMID:16950021.

10. Nam K, Chung S, Kim J, Jeon S, Bae D. Factors associated with HPV persistence after conization in patients with negative margins. J Gynecol Oncol. 2009;20(2):91-5. doi:10.3802/jgo.2009.20.2.91. Epub 2009 Jun 29. PMCID:PMC2705006

11. Heymans J, Benoy IH, Poppe W, Depuydt CE. Type-specific HPV geno-typing improves detection of recurrent high-grade cervical neoplasia after conisation. Int J Cancer. 2011;129(4):903-9. doi:10.1002/ijc.25745. PMID: 21064091, Epub 2011 Feb 11.

12. Bruni $L$, Barrionuevo-Rosas $L$, Albero $G$ et al. Human Papillomavirus and Related Diseases in Romania. In: Summary Report 2016-02-26. ICO Information Centre on HPV and Cancer (HPV Information Centre). http:// www.hpvcentre.net/statistics/reports/ROU.pdf. Accessed 14 July 2016

13. Kim YT, Lee JM, Hur SY, et al. Clearance of human papillomavirus infection after successful conization in patients with cervical intraepithelial neoplasia. Int J Cancer. 2010;126(8):1903-9. doi:10.1002/ijc.24794. PMID:19642095.

14. Song SH, Lee JK, Oh MJ, et al. Persistent HPV infection after conization in patients with negative margins. Gynecol Oncol. 2006;101(3):418-22. PMID: 16386782, Epub 2006 Jan 4.

15. Costa S, De Simone P, Venturoli S, et al. Factors predicting human papillomavirus clearance in cervical intraepithelial neoplasia lesions treated by conization. Gynecol Oncol. 2003;90(2):358-65. PMID:12893200.

16. Sarian LO, Derchain SF, Pitta Dda R, Morais SS, Rabelo-Santos SH. Factors associated with HPV persistence after treatment for high-grade cervical intra-epithelial neoplasia with large loop excision of the transformation zone (LLETZ). J Clin Virol. 2004:31:270-4. PMID:15494268.

17. Park JY, Lee KH, Dong SM, Kang S, Park SY, Seo SS. The association of preconization high-risk HPV load and the persistence of HPV infection and persistence/recurrence of cervical intraepithelial neoplasia after conization. 
Gynecol Oncol. 2008;108(3):549-54. doi:10.1016/j.ygyno.2007.11.009. PMID: 18177929, Epub 2008 Jan 4.

18. Verguts J, Bronselaer B, Donders $G$, et al. Prediction of recurrence after treatment for high-grade cervical intraepithelial neoplasia: the role of human papillomavirus testing and age at conisation. BJOG. 2006;113(11): 1303-7. PMID:16978225, Epub 2006 Sep 15.

19. Ryu A, Nam K, Kwak J, Kim J, Jeon S. Early human papillomavirus testing predicts residual/recurrent disease after LEEP. J Gynecol Oncol. 2012;23(4): 217-25. doi:10.3802/jgo.2012.23.4.217. Epub 2012 Sep 19. PMCID: PMC3469856.

20. Jaisamrarn U, Castellsagué X, Garland SM, et al. Natural History of Progression of HPV Infection to Cervical Lesion or Clearance: Analysis of the Control Arm of the Large, Randomised PATRICIA Study. PLoS One. 2013; 8(11):e79260. doi:10.1371/journal.pone.0079260. eCollection 2013. PMCID: PMC3834039.

Submit your next manuscript to BioMed Central and we will help you at every step:

- We accept pre-submission inquiries

- Our selector tool helps you to find the most relevant journal

- We provide round the clock customer support

- Convenient online submission

- Thorough peer review

- Inclusion in PubMed and all major indexing services

- Maximum visibility for your research

Submit your manuscript at www.biomedcentral.com/submit
Biomed Central 